\title{
Light Unmanned Aerial Vehicles (UAVs) for Cooperative Inspection of PV Plants
}

\author{
Paolo Bellezza Quater, Francesco Grimaccia, Member, IEEE, Sonia Leva, Senior Member, IEEE, \\ Marco Mussetta, Member, IEEE, and Mohammadreza Aghaei, Student Member, IEEE
}

\begin{abstract}
After a fast photovoltaic (PV) expansion in the past decade supported by many governments in Europe, in this postincentive era, one of the most significant open issues in the PV sector is to find appropriate inspection methods to evaluate real PV plant performance and failures. In this context, PV modules are surely the key components affecting the overall system performance; therefore, there is a main concern about the occurrence of any kind of failure in PV modules. This paper aims to propose a novel concept for monitoring PV plants by using light unmanned aerial vehicles (UAVs) or systems (UASs) during their operation and maintenance. The main objectives of this study are to explore and evaluate the use of different UAV technologies and to propose a reliable, cost-effective, and time-saving method for the inspection of PV plants. In this research, different UAVs were employed to inspect a PV array field. For this purpose, some thermal imaging cameras and a visual camera were chosen as monitoring tools to suitably scan PV modules. The first results show that the procedure of utilizing UAV was effective in the detection of different failures of PV modules. Moreover, such a process was much faster and cost effective than traditional methods.
\end{abstract}

Index Terms-Photovoltaic (PV) module, PV system control and monitoring, thermal imaging camera, unmanned aerial vehicle (UAV).

\section{INTRODUCTION}

$\mathbf{N}$ OWADAYS, renewable energy is known as an alternative and sustainable energy that can help to conserve fossil fuels for future generations. In fact, renewable energy can be created by natural sources, which means that they are abundant and there is no need to be concerned about their depletion and replacement in the future. Developed countries have been widely investing in sustainable and alternative energy to make the world full of green and clean energy. Scientists have predicted that mankind will need an additional $30 \mathrm{TW}$ of energy by the mid21 st century, and only the support of photovoltaic (PV) energy promises to meet this challenging target, since solar energy is free and always widely available, even on cloudy days [1].

Solar energy has many advantages: It is environmentally friendly, has decentralized installation, has a long life, requires low maintenance and is noise-free, clean, and light weight.

Manuscript received February 10, 2014; revised April 8, 2014; accepted April 26, 2014. Date of current version June 18, 2014.

P. B. Quater is with Nimbus S.r.1, Lombardore 10040, Italy (e-mail: p.bellezza@nimbus.aero).

F. Grimaccia, S. Leva, M. Mussetta, and M. Aghaei are with the Department of Energy, Politecnico di Milano, Milano 20133, Italy (e-mail: francesco.grimaccia@polimi.it; sonia.leva@polimi.it; marco.mussetta@ polimi.it; mohammadreza.aghaei@polimi.it).

Color versions of one or more of the figures in this paper are available online at http://ieeexplore.ieee.org.

Digital Object Identifier 10.1109/JPHOTOV.2014.2323714
Nevertheless, PV energy is limited due to intermittent power, low-energy density, high startup costs, location, and climate condition dependence. However, a deep investigation concerning the degradation effects in PV modules is quite essential to guarantee the performance and reliability of PV systems [2], [3].

The past decade has seen the rapid development of civil unmanned aerial systems (UASs), also known as remotely piloted aircrafts, to cooperate in monitoring applications such as power transmission line inspection, disaster relief, precision farming, gas and oil pipeline monitoring, weather reconnaissance, pollution and environmental monitoring, port and off shoreline security, arctic ice monitoring, and land mine and forest fire detection. Nevertheless, initially, most of the applications of unmanned aerial vehicles (UAVs) were for military purposes [4].

The aim of this paper is to propose and give a preliminary validation of a cost-effective and rapid monitoring method suitable to inspect PV field array defects by using UAVs. In this light, a family of light UAVs has been employed and tested to detect the common visible, and not visible, failures in solar panels also utilizing a thermal camera. PV array field monitoring by UAVs has many advantages, such as low cost and large area coverage, precise imagery, fast detection, high flexibility, unmanned and easy operations, the ability to operate in harsh environments, and sensible time reduction, which means that a large PV plant can be inspected in a short time to find defects and react with early solutions [5].

This paper is structured in six sections. Section I introduces our proposal about a novel inspection method for PV module monitoring. Section II discusses about the effects of the environmental conditions on the performance of PV modules and the classification of common defects and failure modes. Section III presents traditional inspection methods for PV panel monitoring. Section IV strives to show various aspects of the proposed UAV applications and great potential in the inspection of PV modules. Finally, in Sections V and VI, the experimental investigation is described with geo-referenced captured images taken by the UAVs, drawing some conclusions related to the proposed method.

\section{COMmon Defects ANd FAILURe Modes In PV Modules}

Weather conditions surely affect the PV system performance over time, and various defects can occur in the PV modules even in the short term. Solar irradiation and temperature are the main stress factors that can degrade PV modules. Other weather and environmental conditions-such as, for example, wind, salt, 
hail, snow, dust, and many corrosive gases - can indirectly have an effect in increasing and decreasing these two main factors.

The best performance of PV modules can be obtained at a standard temperature $\left(25^{\circ} \mathrm{C}\right)$. Hence, any excess in PV module temperature can affect the standard performance [6]. Temperature stress can accelerate the chemical degradation of the panels [5], [7]. Therefore, it can lead to creating defects in the PV modules, and eventually the performance of PV systems may decline in a short time [8]. Based on the aforementioned environmental conditions, even in the thin-film solar cell recent development, many defects can appear in PV modules. Therefore, it is useful to first classify the PV module defects to find out an early solution.

According to the investigations, most visible failures appear in the PV modules due to the polymers' defects such as delamination, bubbles, cracking, or yellowing [9]. Discoloration, oxidation, and corrosion of connectors' defects can also affect the PV modules' electrical characteristics, but their inspection is quite easy by visual observation. Other phenomena such as snail trails, shading, hot spots, microcracks, and cell breakage defects can have the highest influences on the performance of the PV modules as discussed later on. These kinds of failures can, in fact, be better detected using also thermal and infrared cameras.

Yellowing and browning can appear in PV modules due to dry heat (e.g., due to desert climate), high UV radiations, and humidity. Moreover, it can occur because of insufficient adhesion between cells and glass material. However, this creates an obstacle between solar cells and sunlight, which leads to compromising PV modules' voltage output.

The corrosion will occur in PV modules' glass and metal because of the combination of gasses and humidity. Snow and wind can produce a higher static load; hence, they can break PV modules' glass due to the mechanical load for dynamic and static reasons. In the desert climate for example, sand, wind, and dust significantly decrease the performance of PV modules [5], [10]. Furthermore, glass breakage can be caused by bumps.

Adherence loss among PV modules' layers usually causes delamination. Typically, it happens between cells and front glass or between polymeric encapsulant and cells. This defect can increase reflection, and the water can then penetrate into the module itself. Nevertheless, a delamination defect in the borders of the PV module causes both electrical and installation risks and likely transmittance losses [11].

On the other hand, bubble defect is more similar to delamination, while adherence losses occur only in some areas of PV modules due to chemical reactions. Generally, bubble defects occur in the backside and not in the front side of the PV module. In fact, a bulk in the back cover or polymeric encapsulant prevents the dissipation of heat from the solar cells [12].

In recent years, manufacturers have produced thin solar cells, and the thicknesses of absorber layers have reached values around $100 \mu \mathrm{m}$ or even less. Moreover, it should be mentioned that the area of the solar cells has been increased to $210 \mathrm{~mm}^{2}$ [13]. These changes can make the solar cells more sensitive and fragile during shipment and installation. Microcrack defects can appear as some different color lines on both sides of the PV

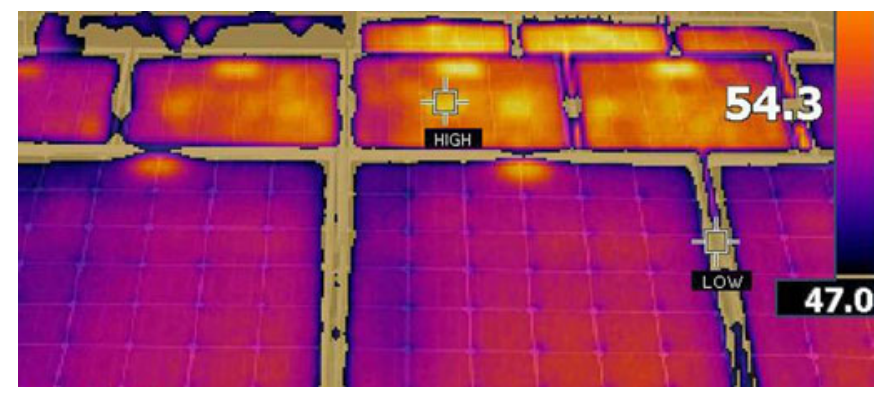

Fig. 1. Thermal image of different PV modules: healthy ones (1st row), affected by hot-spot phenomena (2nd row) and those with a complete overheated surface (3rd row).

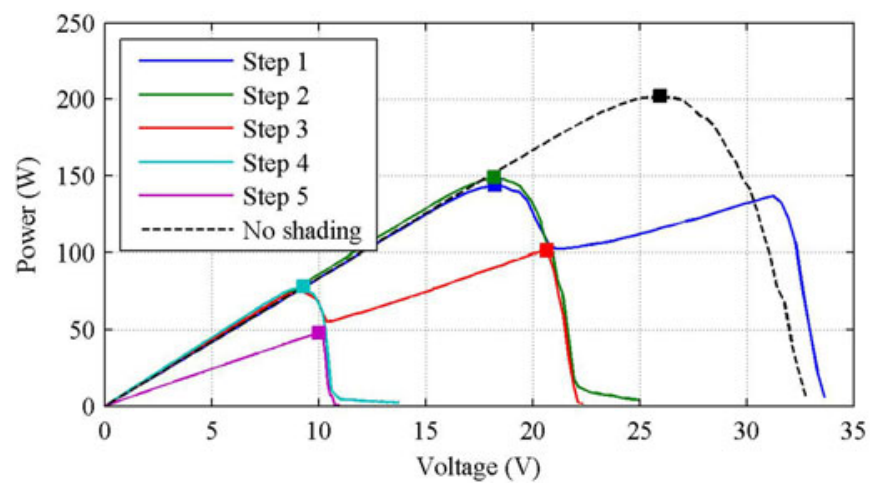

Fig. 2. $\quad P-V$ characteristic of multiple diagonal steps shadowing effects on the same module (from [15]).

module, and they can be detected only using special devices such as thermal and infrared cameras or by the optical method. This failure causes a decline in solar cell consistency and it could also lead to an increase in the carrier recombination path. In addition, the cracks' effect compromises energy conversion, and it seriously affects the current generation due to isolation properties.

Antireflective coating is used in PV modules so that maximum sunlight can reach to the modules. The antireflective coating is subjected to solar radiation; hence, its color may change. In this regard, the characteristics of antireflective coating changes the sun reaching mechanism to the solar cell which is reduced. However, the main reason of this failure is oxidation and it can lead to adherence loss between the glass and the solar cell; thus, the voltage can accelerate oxidation on the antireflective coating.

One of most significant defects is the hot-spot failure, which is defined as an area on the PV module with higher temperature, as shown in Fig. 1. The hot spot can damage the solar cell and other components of the PV system. Typically, the reasons of the hot-spot defect include mismatch of solar cells, partial shadowing, or any failure in the interconnection between the solar cells [14]

When the solar cells are subjected to shadowing, they may operate reversely as loads, as shown in Fig. 2. Therefore, in this case, the solar cells consume energy instead of generating it [15]. In addition, sufficient protection can prevent hot spots 


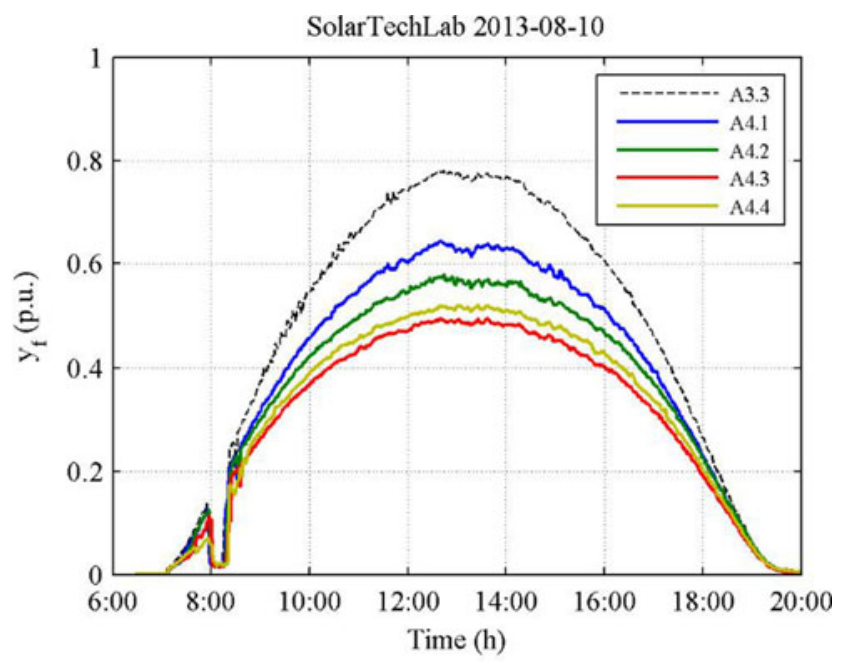

Fig. 3. PV modules performance evaluation: A4.1 to A4.4 modules are affected by snail trails; A3.3 is a healthy module.

from appearing when partial shadowing is present on the PV modules. Bypass diodes can also be used in the connections to avoid overheating and hot spots. They limit the reverse voltage and thereby temperature reduction in the PV modules.

Sometimes the hot spot can occur due to the shunt resistance. This shunt resistance can appear because of a shortcut or an error in interconnections in the solar cell, which may happen during the manufacturing process. Once a solar cell generates lower currents than other solar cells, a mismatch occurs among the modules. Hot spots can easily be detected by thermal cameras.

Finally, the PV modules can be subjected to a defect known as the snail trail phenomenon. The snail trail impact emerges on the PV modules' edge because of both environmental conditions and manufacturing process. They appear as dark and small lines or solar cell discoloration on the PV modules. Furthermore, snail trails can occur if the PV cell is produced as thin thickness, and in this case, it cannot compromise efficiency too much [16].

Experimental tests show that the performance of PV modules affected by snail trails decreases by more than $20 \%$ if compared with a healthy module as shown in Fig. 3, where the instantaneous final yield $y_{f}$ is reported

$$
y_{f}=\frac{P(t)}{P_{R}}
$$

where $P(t)$ is the instantaneous power, and $P_{R}$ is the rated power.

\section{Common Detection Methods}

Generally, the failures in PV systems can be classified into two categories: those related to the overall PV system and those concerning single PV modules. The choice of suitable inspection methods is critical to detect any fault in the PV modules in particular. Moreover, early failure detection plays a significant role in maintaining the performance of PV modules over time. In fact, it can prevent extending failures to other nondefective modules. Hence, the rapid recognition of module defects can keep the PV system performances high. Nevertheless, most of the detection methods either for PV systems or for PV modules are quite expensive; in fact, the use of many sensors or the employment of inspectors for monitoring is generally not cost-efficient and acceptable for large PV fields. Regardless of economical aspects, the data collection and processing procedure usually takes time, and its complexity increases with the PV system size.

Thus, in the future, we can expect a growing attention to investigation on reliable and cost-effective methods for PV module monitoring. Nowadays, there are different inspection methods for PV modules, some of which are presented below.

\section{A. Visual Detection}

Typically, inspection by sight is the first method of evaluation of failures of PV modules. In this method, cracks, yellowing, misalignment, delaminations, bubbles, snail trails, and brunt cells can often be observed. After this step, the experts can make a decision about further inspection and actions to be taken.

\section{B. Photovoltaic Parameters' Measurement}

Defects in PV modules can be found by measuring the output under standard test conditions (STC-temperature: $25^{\circ} \mathrm{C}$, radiation: $1000 \mathrm{~W} / \mathrm{m}^{2}$, AM 1.5). The measurement test can be performed either outdoor, under sunlight radiation, or indoor, using solar simulators. Although the environmental condition can be better controlled indoor, the measurement is less significant in terms of actual conditions, since temperature will usually be above STC [17], [18].

\section{Using Infrared and Thermal Cameras}

Thermal and infrared cameras can be used to detect hightemperature regions on the PV module surface. Therefore, a thermographic technique can be employed to detect defects in PV modules, such as for example hot spots by using highresolution thermal or infrared cameras in the PV array field [19], [20]. Of course, for correct identification of the failure, modules showing anomalies must also be inspected visually and tested electrically. In the following, a cooperative monitoring approach using photo and thermal cameras is presented, in order to combine both visual inspection and thermal analysis in an automated procedure for large PV field monitoring.

\section{UNMANNED AERIAL VEHICLE}

Recent advances in the aerial industry technology, sensors, technical cameras, and control systems have made it possible to employ UAVs in inspecting and monitoring large areas [21]. Therefore, the identification of suitable UAV characteristics requires specific investigations and studies for possible and appropriate application in various fields.

Currently, UAVs are used basically for monitoring power transmission line [22], disaster relief, wildlife, gas and oil pipelines, weather reconnaissance, pollution and environmental monitoring, port and off-shore line security, arctic ice, land mine, forest fire detection, and even in civil applications. 
However, the advantages of UAVs in comparison with manned aircraft monitoring are their intrinsic safety (e.g., no risk for the pilot in dangerous remote missions), low weight, and cost-effectiveness; moreover, large amounts of data can be collected by various sensors and cameras, and several other monitoring applications can be implemented [23], [24]. Since UAVs can carry various detectors, sensors, and cameras to inspect defects on the monitored systems, the main objective of this study is to determine the possibility of applying UAVs to monitor visible and invisible defects on the PV modules in a small or huge field area by photo- and thermal-camera devices [25].

In fact, there are many advantages of using UAVs for this cooperative monitoring of PV fields: Since the PV modules' lifetime depends on proper monitoring and inspection, precise information of module degradation is critical in PV systems to reduce the financial risk.

\section{A. System Description}

With respect to the UAV regulation achievements, in order to properly operate with UAS technology in this sector, it is important to emphasize that the peculiarities of the considered activities request the grant of proper Permit to Fly to be able to operate in real field operations. For this reason, the platforms considered here are the ones manufactured by Nimbus, an Italian SME active in the UAV design and production, since in the past few years, it has already received multiple Permits to Fly from the Italian Civil Aviation Certification Authority. In fact, the novel-patented UAV platforms represent, in this light, the first case in Italy in the category of the so-called light UAV and promise to open up new market opportunities in PV plant performance monitoring. Moreover, according to the certification prescriptions, the construction characteristics of these technologies make them harmless in terms of materials, geometry, and kinetic energy of impact.

In this investigation, two different UASs have been employed to inspect the PV modules' conditions: Nimbus EosXi UAV (see Fig. 4) for a first analysis and Nimbus PLP6 (see Fig. 5) for an in-depth analysis and detailed information about the plant. Both of them can be classified in the light UAS segment. In fact, the use of UAVs can reduce the monitoring cost much more than the other methods. Inspection by this method will be fast and it can save monitoring time. Therefore, this method can be appropriate for small and large PV array fields to find out PV modules' degradation and other failures. However, the early recognition of defects can prevent extending PV modules' degradation and wasting energy. The key aspects of UAV application in PV module monitoring include flexibility, fast detection of a large PV array field, and cost-effectiveness.

The characteristics and main features of Nimbus EosXi UAV and Nimbus PLP6 are compared in Table I, in terms of the cruise speed, endurance, and main operational constraints.

However, it should be mentioned that UAVs cannot operate alone in PV module monitoring; they require ad hoc sensors onboard to be used as inspection tools. Therefore, it is suggested to use appropriate cameras to detect different PV module failures

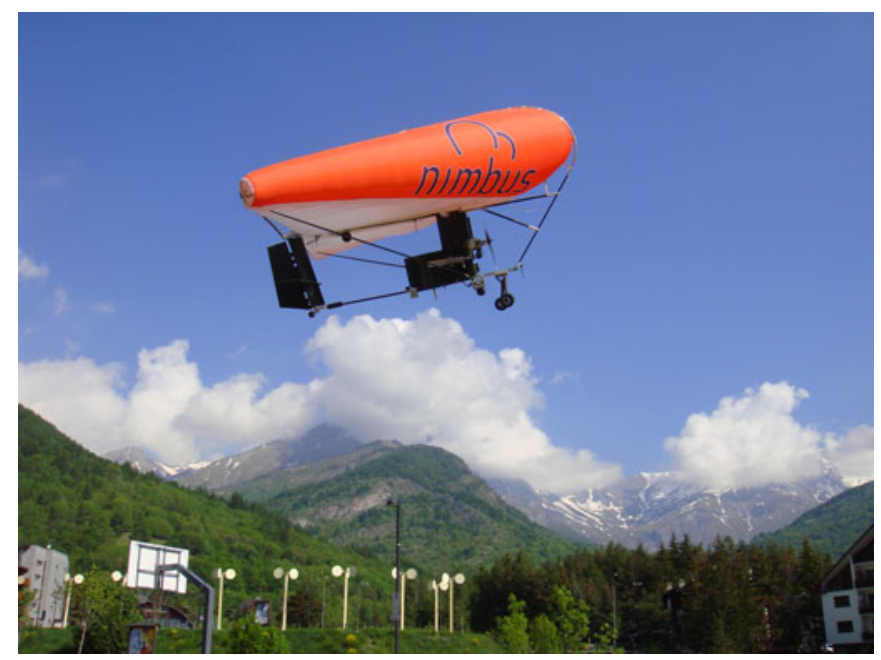

Fig. 4. Nimbus EosXi UAV platform.

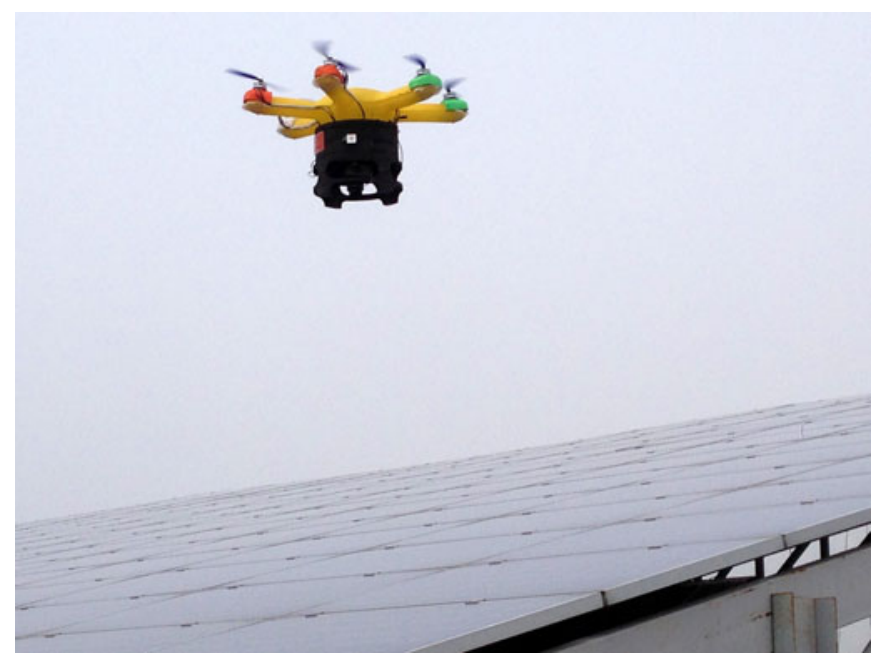

Fig. 5. Nimbus PLP6 during PV monitoring operation.

TABLE I

UAV FEATURES

\begin{tabular}{ccc}
\hline \hline Items & NIMBUS EOSXI & NIMBUS PLP6 \\
\hline Cruise Speed & $13-17 \mathrm{kts}$ & $0-15 \mathrm{kts}$ \\
Operational range & $5 \mathrm{Km}$ & $0.5 \mathrm{Km}$ \\
Max Altitude & $500 \mathrm{ft}$ & $150-200 \mathrm{ft}$ \\
Flight Endurance & $<3 \mathrm{~h}$ & $0.25-0.5 \mathrm{~h}$ \\
Weight & $64 \mathrm{Kg}$ & $3.3 \mathrm{Kg}$ \\
Height & $3 \mathrm{~m}$ & $0.3 \mathrm{~m}$ \\
Length & $5 \mathrm{~m}$ & $(\varnothing) 0.8 \mathrm{~m}$ \\
Wing span & $6 \mathrm{~m}$ & $\mathrm{NA}$ \\
Propulsion & Gasoline engine & Electric Power \\
\hline \hline
\end{tabular}

in production plants. Another useful feature both for thermal imaging and for visual captures is the tagging of images with GPS data. This helps to localize faulty modules easily in large areas. 


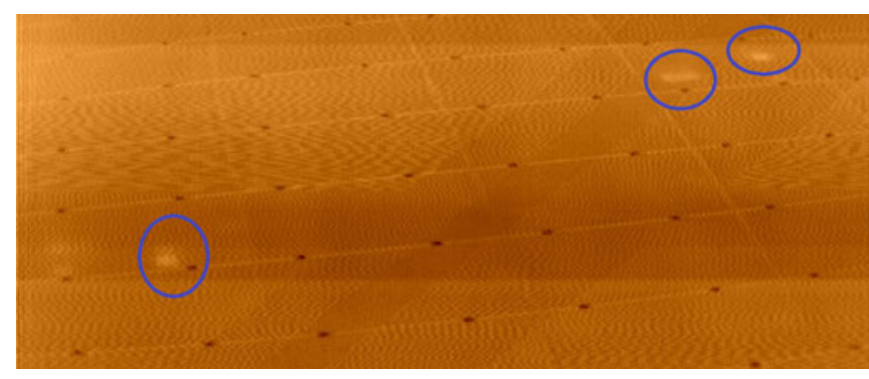

Fig. 6. Different hot areas captured by a thermal camera.

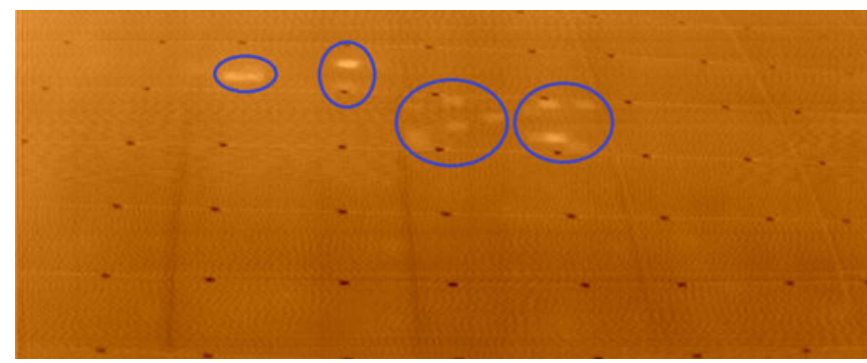

Fig. 7. Sample "patchwork pattern" detected in the monitored plant.

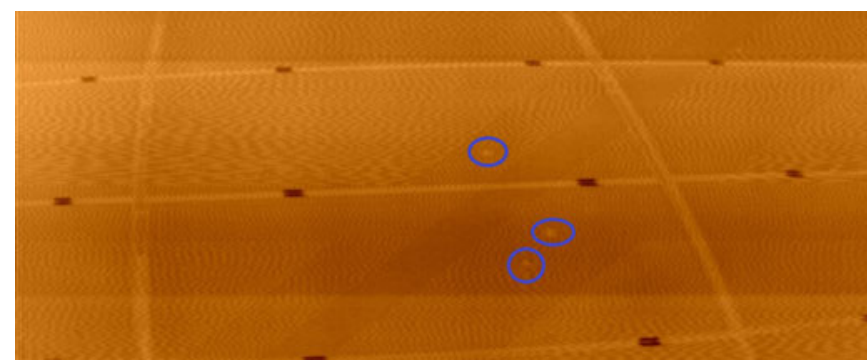

Fig. 8. Example of single hot spots in PV modules.

\section{ANALYSIS AND RESULTS}

In this paper, different kinds of sensors have been used in a first trial campaign to detect PV module failures, namely a thermal camera (MicroCAM 640 by Thermoteknix Systems Ltd.) and an HD photocamera (Nikon1-v1), which were mounted on the Nimbus EosXi and Nimbus PLP6 platforms to capture precise pictures and videos of PV panel defects, both in the visible and infrared ranges. Thermal imaging cameras show themselves to be reliable and fast tools for PV module evaluation. Using thermal cameras in PV module inspection has more advantages than using other monitoring devices. In fact, thermal cameras can be used to scan PV modules during their normal operation with no need of system shutdown. Moreover, thermal cameras on UAVs can scan a large PV array field within a short time frame. However, a visual inspection can be used to correct identification of the failure. The use of UAVs allows us to analyze large areas in a short time, where there is both thermal imaging and visual imaging.

The PV system under analysis is in the north of Italy and its power is $200 \mathrm{~kW}$ with 810 polycrystalline silicon modules

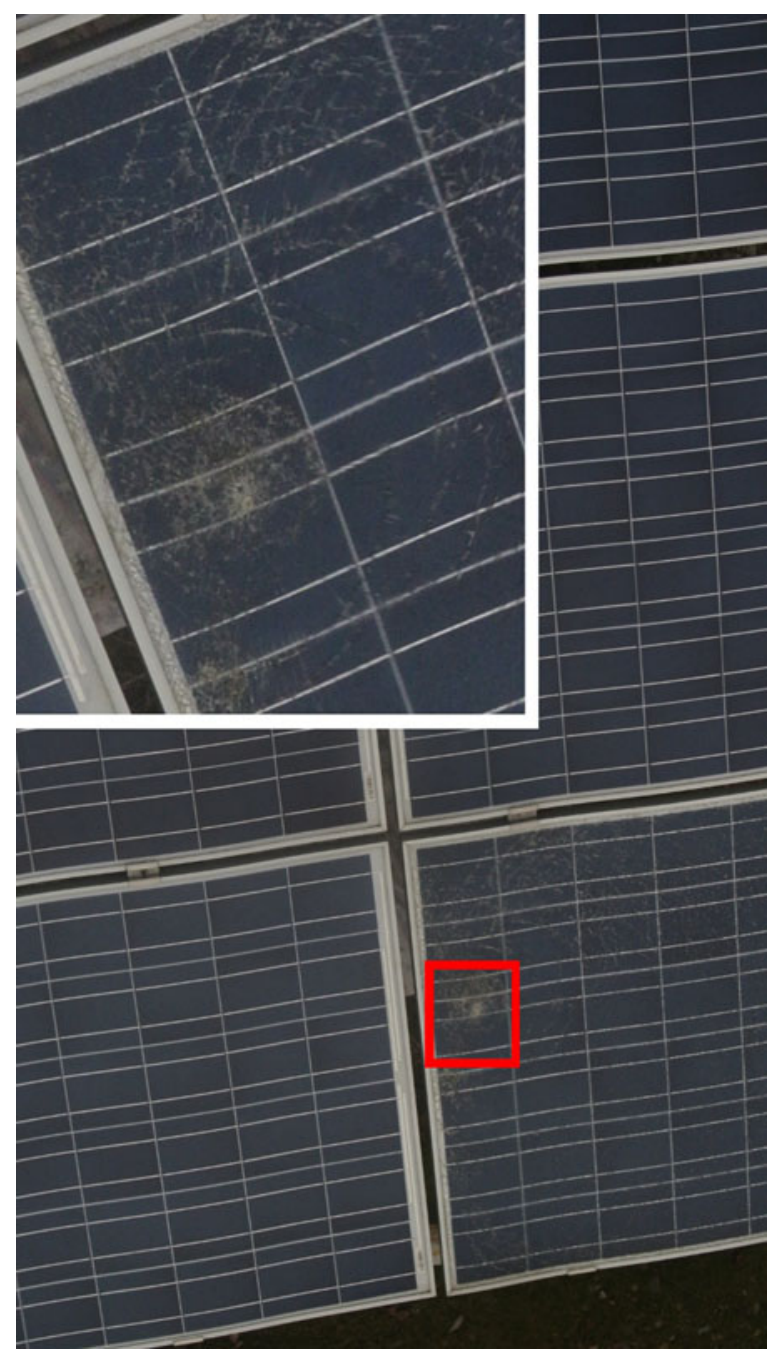

Fig. 9. Picture captured by a Nikon1-v1 camera with inlet detail of a particular shock-defect.

installed on a shelter. The PV plant is connected to the mediumvoltage grid by means of 27 inverters and a single transformer.

First of all, a preliminary analysis was made using the bigger Nimbus EosXi UAV platform for an overall view of the plant. Figs. 6-8 have been captured by a MicroCAM 640 thermal camera.

As shown in Fig. 6, some defective points have been detected in different areas of the PV field. Depending on their shape and location, these hot spots and hot areas can highlight different faults. Usually, if an entire module is warmer than usual, as partially shown in Fig. 1 (taken by a Fluke Ti 25 thermal camera), then some interconnection problems can be envisaged. On the other hand, if single cells or strings of cells are showing up as a hot spot or a warmer "patchwork pattern," as shown in Fig. 7, the reason can usually be found either in defective bypass diodes, internal short-circuits, or in a cell mismatch, as well as due to snail trails phenomenon. Sometimes, shadowing and cracks in cells show up as hot spots (see Fig. 8) or polygonal patches in the thermal image. The temperature rise of a cell (or part of it) indicates a defective cell or shadowing. 


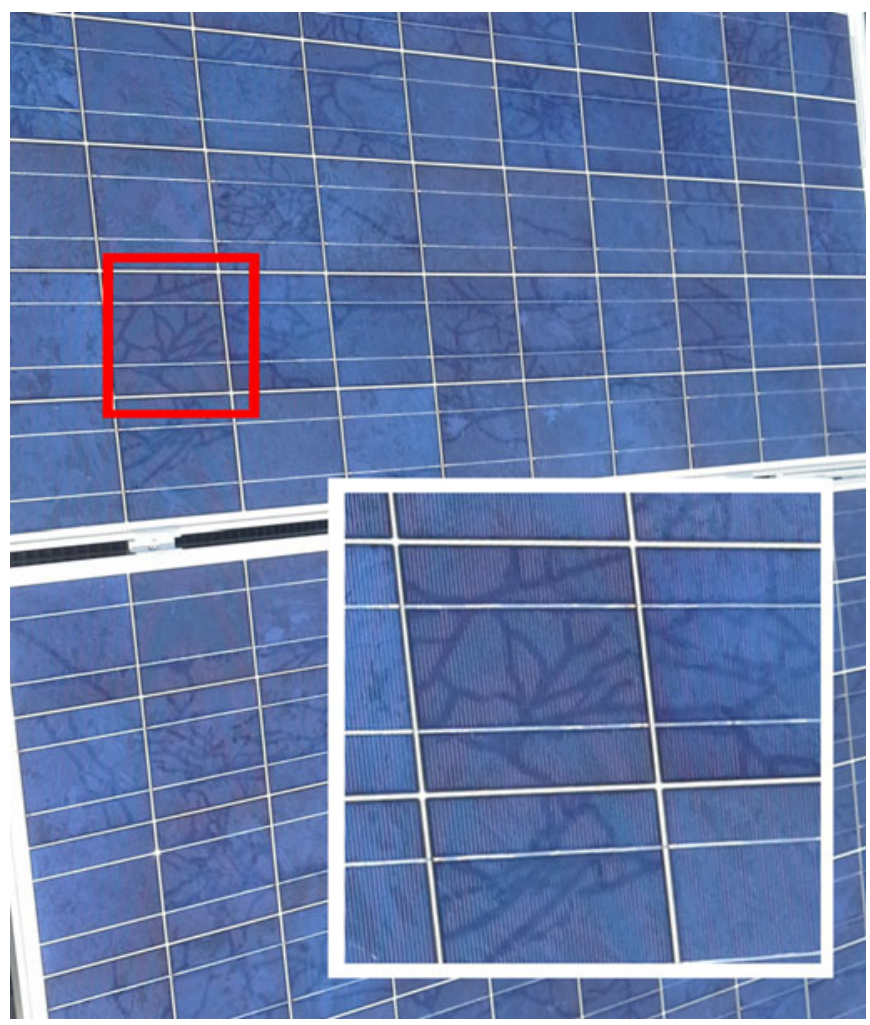

Fig. 10. Picture captured by a Nikon camera with a module affected by snail trails.

However, the distance between the PV array and the UAV in this case did not allow the accurate identification of additional information on the type of problem that was causing the overheating of some cells. The use of the second type of UAV allows us to get closer to the shelter and, consequently, to the modules. In this case, we performed a second analysis using a different sensor, namely a camera in the visible range. Figs. 9 and 10 show some of the results obtained. First picture shows that the defect detected by the thermal analysis is because of breaking of the glass (a mechanical shock). The second picture shows the snail trail phenomenon.

In order to give some estimate of the system cost, according to our preliminary test analysis, using the light UAS described in Section III-A, it is possible to reach an optimal quality-price ratio if three or four small plants are located in the same area, or on the contrary, a unique big plant is inspected in a single day. The described system was targeted for a plant size of around 0.2-1 MW, and some scale effect can be envisaged in terms of logistic costs [26]. However, since the operating cost of such vehicles is very low, when compared with traditional aircrafts or helicopters, the overall system cost can be evaluated by less than $5 \%$ of the average annual maintenance cost for the cited plant size, but the potential benefits resulting from the inspection can multiply the value with respect to the initial expenditure for the monitoring system.

\section{CONCLUSION}

Solar modules are the key components in a PV plant system, and they play a fundamental role in the conversion of solar radiation and related energy output performance. Even if the solar energy cost is decreasing due to investment in thin-film technology and other developments, it is still high if compared with other sources in many countries. However, in the near future, the cost and efficiency of PV systems can be optimized by appropriate monitoring and maintenance activities both for small- and large-sized plants. In this context, the monitoring with related technological solutions can have a significant impact to obtain the best performance and solutions from the installed capacity.

In this paper, a novel monitoring concept using light UAVs is proposed to detect different kinds of PV modules' failures. In this regard, the current investigation was conducted to determine the real feasibility of UAS technology in PV array field inspection and evaluate data captured by different sensors mounted onboard. In future work, a methodology to automatically correlate specific sensor data with the defects in PV modules' will be investigated in order to obtain fast and reliable results, which are especially useful for large-sized PV plant activities such as performance analysis, operation and maintenance, and revamping.

\section{REFERENCES}

[1] G. E. Tverberg, "Oil supply limits and the continuing financial crisis," Energy, vol. 37, pp. 27-34, 2012.

[2] G. Petrone, G. Spagnuolo, R. Teodorescu, M. Veerachary, and M. Vitelli, "Reliability issues in photovoltaic power processing systems," IEEE Trans. Ind. Electron., vol. 55, no. 7, pp. 2569-2580, Jul. 2008.

[3] A. Golnas, "PV system reliability: An operator's perspective," IEEE J. Photovoltaics, vol. 3, no. 1, pp. 416-421, Jan. 2013.

[4] L. C. Trost, "Unmanned air vehicles (UAVs) for cooperative monitoring," Sandia Nat. Labs., Albuquerque, NM, USA, 2000.

[5] C. Ferrara and D. Philipp, "Why do PV modules fail?" Energy Procedia, vol. 15, pp. 379-387, 2012.

[6] T. M. Walsh, Z. Xiong, Y. S. Khoo, A. A. Tay, and A. G. Aberle, "Singapore modules-optimised PV modules for the tropics," Energy Procedia, vol. 15, pp. 388-395, 2012.

[7] E. L. Meyer and E. E. van Dyk, "Assessing the reliability and degradation of photovoltaic module performance parameters," IEEE Trans. Rel., vol. 53, no. 1, pp. 83-92, Mar. 2004.

[8] E. Van Dyk, E. Meyer, A. Leitch, and B. Scott, "Temperature dependence of performance of crystalline silicon photovoltaic modules," South African J. Sci., vol. 96, 2000.

[9] M. Abdelhamid, R. Singh, and M. Omar, "Review of microcrack detection techniques for silicon solar cells," IEEE J. Photovoltaics, vol. 4, no. 1, pp. 514-524, Jan. 2014.

[10] M. P. P. Snchez-Friera, J. C. J. Pelez, and M. S. de Cardona, "Analysis of degradation mechanisms of crystalline silicon PV modules after 12 years of operation in Southern Europe," Progress Photovoltaics: Res. Appl., vol. 19, pp. 658-666, 2011.

[11] A. Skoczek, T. Sample, E. Dunlop, and H. Ossenbrink, "Electrical performance results from physical stress testing of commercial PV modules to the IEC 61215 test sequence," Sol. Energy Mater. Sol. Cells, vol. 92, pp. 1593-1604, 2008.

[12] S. Mau, T. Krametz, W. Jahna, and H. Fechner, "Quality testing for PVmodules according to standards and performance control for supporting manufacturing," presented at the 19th Eur. Photovoltaic Sol. Energy Conf. Exhib., Paris, France, 2004.

[13] W. Dallas, O. Polupan, and S. Ostapenko, "Resonance ultrasonic vibrations for crack detection in photovoltaic silicon wafers," Meas. Sci. Technol., vol. 18, p. 852, 2007.

[14] E. Molenbroek, D. Waddington, and K. Emery, "Hot spot susceptibility and testing of PV modules," in Proc. 22nd Photovoltaic Spec. Conf., 1991, pp. 547-552.

[15] A. Dolara, G. C. Lazaroiu, S. Leva, and G. Manzolini, "Experimental investigation of partial shading scenarios on PV (photovoltaic) modules," Energy, vol. 55, pp. 466-475, 2013. 
[16] S. Meyer, S. Richter, S. Timmel, M. Glser, M. Werner, S. Swatek, and C. Hagendorf, "Snail trails: Root cause analysis and test procedures," Energy Procedia, vol. 38, pp. 498-505, 2013.

[17] J. Roy, G. R. Gariki, and V. Nagalakhsmi, "Reference module selection criteria for accurate testing of photovoltaic (PV) panels," Sol. Energy, vol. 84, pp. 32-36, 2010.

[18] J. Rosell and M. Ibanez, "Modelling power output in photovoltaic modules for outdoor operating conditions," Energy Convers. Manage., vol. 47, pp. 2424-2430, 2006.

[19] J. A. Tsanakas and P. N. Botsaris, "An infrared thermographic approach as a hot spot detection tool for photovoltaic modules using image histogram and line profile analysis," Int. J. Condition Monitoring, vol. 2, no. 1, pp. 22-30, 2012.

[20] J. A. Tsanakas and P. N. Botsaris, "On the detection of hot spot analysis in operating photovoltaic arrays through image analysis and a simulation model," Mater. Evaluation, pp. 457-465, 2013.

[21] K. Nonami, "Prospect and recent research \& development for civil use autonomous unmanned aircraft as UAV and MAV," J. Syst. Design Dyn., vol. 1, pp. 120-128, 2007.

[22] Z. Li, Y. Liu, R. Walker, R. Hayward, and J. Zhang, "Towards automatic power line detection for a UAV surveillance system using pulse coupled neural filter and an improved Hough transform," Mach. Vision Appl., vol. 21, pp. 677-686, 2010 .

[23] D. Hausamann, W. Zirnig, G. Schreier, and P. Strobl, "Monitoring of gas pipelinesa civil UAV application," Aircraft Eng. Aerosp. Technol., vol. 77, pp. 352-360, 2005.

[24] H. Eisenbeiss, "A mini unmanned aerial vehicle (UAV): System overview and image acquisition," Int. Archives Photogrammetry. Remote Sensing Spatial Inf. Sci., vol. 36, 2004.

[25] S. Montambault and N. Pouliot, "The HQ LineROVer: Contributing to innovation in transmission line maintenance," in Proc. 10th Int. Conf. Transmiss. Distrib. Construction, Operation Live-Line Maintenance, 2003, pp. 33-40.

[26] A. Dolara, F. Grimaccia, S. Leva, M. Mussetta, R. Faranda, and M. Gualdoni, "Performance analysis of a single-axis tracking PV system," IEEE J. Photovoltaics, vol. 2, no. 4, pp. 524-531, Oct. 2012.

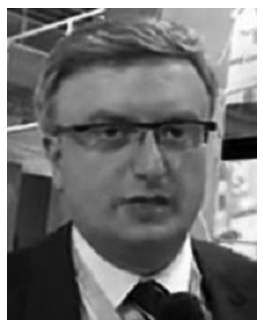

Paolo Bellezza Quater received the M.Sc. degree in mechanical engineering.

He is currently the CEO of Nimbus S.r.1., Lombardore, Italy, where he is the ARIS SpA Board Member with R\&D responsibility. He was the Technical Director in ARIS SpA, in charge of the direction and coordination of all the working teams related to the design, computational fluid dynamics, computeraided engineering, prototyping, and testing of vehicles and complete systems. Moreover, he holds, as Inventor or Leading Inventor, more than 20 national and international patents. He is currently in the Board of Directors of API Torino SME Association, chairing the Commission for Innovation.

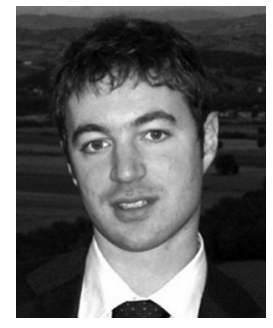

Francesco Grimaccia (S'04-M'09) received the M.S. and Ph.D. degrees in electrical engineering from the Politecnico di Milano, Milano, Italy, in 2003 and 2007, respectively.

$\mathrm{He}$ is currently an Assistant Professor with the Department of Energy, Politecnico di Milano. His main research interests include soft-computing technique development and application in different fields, such as wireless sensor networks, photovoltaics, unmanned aerial systems, and energy-harvesting devices.

Dr. Grimaccia is a Member of the IEEE Computational Intelligence Society, the Society of Photo-Optical Instrumentation Engineers, and the President of the AEIT Young Engineers Society.

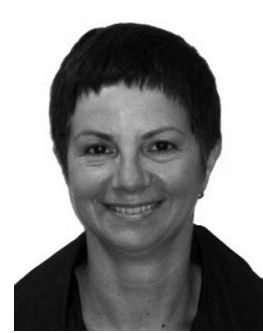

Sonia Leva (M'00-SM'13) received the M.S. and $\mathrm{Ph} . \mathrm{D}$. degrees in electrical engineering from Politecnico di Milano, Milano, Italy, in 1997 and 2001, respectively.

She is currently an Associate Professor of Electrical Engineering with the Department of Energy, Politecnico di Milano. Her research interests include electromagnetic compatibility, power quality, and renewable energy analysis and modeling. She is member of the Italian Standard Authority (CEI/CT82) and of the IEEE Working Group "Distributed Resources: Modeling \& Analysis, " as well as the Task Force on "Modeling and Analysis of Electronically Coupled Distributed Resources."

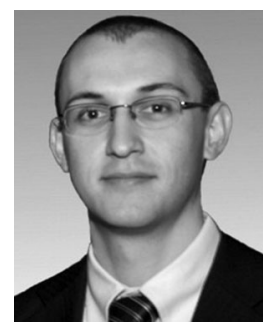

Marco Mussetta (S'03-M'08) received the M.S. and $\mathrm{Ph} . \mathrm{D}$. degrees in electrical engineering from Politecnico di Milano, Milano, Italy, in 2003 and 2007, respectively.

He is currently an Assistant Professor with the Department of Energy, Politecnico di Milano. His main research interests include soft-computing technique development and application in different fields, such as electromagnetic devices, wireless sensor networks, and photovoltaic and other energy-harvesting devices.

Dr. Mussetta is a Member of the IEEE Power Engineering Society, the IEEE Computational Intelligence Society, and the Spanish Association of Telecommunication Engineers.

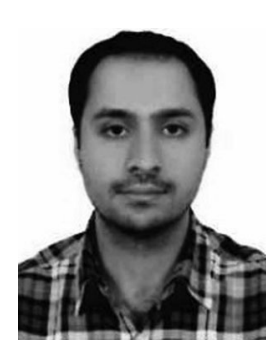

Mohammadreza Aghaei (S'12) received the B.S. degree in electronics engineering from Azad University, Tehran, Iran, in 2009 and the M.S. degree in electrical engineering from the Universiti Tenaga $\mathrm{Na}-$ sional, Selangor, Malaysia, in 2013. He is currently working toward the Ph.D. degree with the Politecnico di Milano, Milano, Italy.

His research interests include power electronics, photovoltaic systems, photonics, renewable sources, and unmanned aerial vehicles. 